\title{
Review of general, organic, and biological chemistry, second edition
}

\author{
Shadi Abu-Baker", Shahrokh Ghaffari, Mohannad Al-Saghir, Parinbam K. Thamburaj
}

College of Arts and Sciences, Ohio University, Zanesville, USA; ${ }^{*}$ Corresponding Author: abu@ohio.edu

Received 4 December 2013; revised 4 January 2014; accepted 11 January 2014

Copyright (C) 2014 Shadi Abu-Baker et al. This is an open access article distributed under the Creative Commons Attribution License, which permits unrestricted use, distribution, and reproduction in any medium, provided the original work is properly cited. In accordance of the Creative Commons Attribution License all Copyrights (C) 2014 are reserved for SCIRP and the owner of the intellectual property Shadi Abu-Baker et al. All Copyright (C) 2014 are guarded by law and by SCIRP as a guardian.

\section{ABSTRACT}

Overall, General, Organic, and Biological Chemistry is a very useful text to support a twosemester undergraduate course series in chemistry for health sciences students. Its strengths are the use of the P.A.V.E. way to student learning applications. It is very obvious that the author has the background and the preparation of the student taking the course(s) in mind when she was writing the textbook.

\section{KEYWORDS}

\section{Text Book Review; Education; Chemistry; Biochemistry; Organic}

\section{INTRODUCTION}

Chemistry departments in many institutions of higher education offer "service" courses to support allied health major programs such as nursing or non-science majors such as education. The chemistry course(s) taken by these students may also be a prerequisite for biology courses taken by these students (microbiology for example). Typically these students are not particularly strong in mathematics. It is not uncommon that these students, particularly those attending community colleges and/or two year colleges, had taken no chemistry in high school. The chemistry courses taken by these students should prepare them to understand relationships between different properties of matter (such as direct proportion, inverse proportion etc.), which are encountered not only in other courses, and they are required to take but in real life as well. This may be a strong reason why "gaseous laws", a highly math intensive chapter, is a part of all introductory chemistry textbooks in the market. "Chemistry Without Math" may be a catchy phrase to sell text books, but it is not reality! To understand concepts in biology, students need to have fundamental understanding about organic matter. A clear understanding of atomic structure and chemical bonding (particularly about covalent bonding) is a must to "see" how biological transformations occur. A modest dose of biochemistry is also helpful. These are essentials to make the chemistry course(s) really a service course for allied health majors. Such a situation affects the construction of the syllabi of these courses and the essentials are also useful as a "screen" to evaluate available textbooks in the market. Finding the right chemistry textbook for the firstyear undergraduate students for professions that deal with biological transformations such as nursing is a challenge for many chemistry instructors [1-4]. Increasing number of chemistry faculty believes that chemistry with an emphasis on applications in biological systems should be taught to non-chemistry majors. Janice Gorzynski Smith of the University of Hawaii at Manoa has presented an excellent addition to the list of textbooks available to meet the special need of these students, via General, Organic, and Biological Chemistry. Professor Smith has demonstrated that it is possible to find a delicate balance between topics in general, organic chemistry and biochemistry in a textbook to meet this need!

\section{THREE BROAD TEXT CATEGORIES}

General, Organic, and Biological Chemistry is designed to support a two-semester or three-quarters course series and is presented in twenty four chapters. Smith breaks the chemistry text into the three broad categories (general chemistry in first 10 chapters, organic in 8 chapters and biochemistry in 6 chapters). Typically for an instructor who wants to use this book in two semesters (for health science majors including nursing), the general chemistry part of the book (first 10 chapters) will be covered in first semester and the selective topics from 
organic and biochemistry part will be taught in the second semester (Chapter 11 - 24). To help the instructor to manage the course in a timely manner, it would be of great benefit if the author of the book publishes a 20-chapter version of the book that reduces and simplify the organic and biochemistry part of the book to ten chapters.

\section{GENERAL CHEMISTRY CHAPTERS}

The general chemistry part (first ten chapters) introduces students to topics that includes matter and measurement, atoms and the periodic table, ionic and covalent compounds, chemical reactions, energy changes, reaction rates and equilibrium, physical states of matter, solutions, acids and bases, and nuclear chemistry. The first chapter should be very useful for health sciences such as nursing as it introduces students to all sorts of measurements and conversions. The student should be able to convert weights and heights of their patients between the metric and the British system of measurements. In addition, several detailed examples are presented on determination of density and on converting temperature measurements between Fahrenheit and Celsius. In this part it should be clear that basic SI unit for volume is not "liter" but " $\mathrm{m}$ ". . The other units of volume " $\mathrm{mL}$ " and

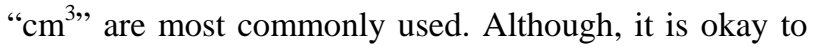
mention about "cc" but since it is not only used in scientific literatures but most recently use of "cc" is avoided in medical field as well. Authors also find Figure 1.6 is a kind of confusing for students. The students then will learn about the groups and periods of the periodic table and understand the differences between covalent and ionic bonds. Then, students will get introduced to balancing chemical equations using biological examples such as photosynthesis. Smith also did a very good job of just giving right amount of coverage of heat of reaction, rate of chemical reaction, and chemical equilibrium in Chapter 6. She is using examples and tables to summarize the effect of different changes on both rate of reaction and chemical equilibrium. Chapter 7 covers appropriate amount of material covering gas laws. However, an introduction of diffusion and effusion of gasses would be appropriate here. In this chapter Section 7 and beyond can be separated into another chapter. Chapter 8 about solutions covers very important topics to the health sciences students including details about dilution, osmosis, dialysis and units of concentration for solutions. Chapter 9 about acid-base equilibrium covers some physiological applications and it has a very interesting figure about the anatomy of the gastrointestinal tract (GIT) with arrows pointing to the $\mathrm{pH}$ at different organs along the GIT system. The last chapter of the general chemistry section is about nuclear chemistry and it has useful applications related to health and medicine such as the use of radioisotopes in the diagnosis and treatment of several types of cancer using illustration of human body.

\section{ORGANIC CHEMISTRY CHAPTERS}

The organic chemistry is the second area of this text which is presented in 8 chapters. It focuses on shape of molecules and the functional groups and their reactions and application to medicine (alkane, unsaturated hydrocarbons, aldehydes and ketones, carboxylic acids, esters, amides and amines). The organic material development of chapters is straightforward for non-majors including nursing. Each chapter has numerous examples and problems to reinforce the reactions learnt and nomenclature of organic chemistry functional groups. Every chapter in this part includes a very interesting section that connects the topic to health matters and human body. For example in Chapter 11, a section about how to make straight hair curly (the disulfide bonds holding the hair proteins together are reduced) and a section about the aroma or taste of fruits such as banana, mango, and citrus (relate that to the functional groups of the corresponding molecule). In Chapter 12, there is a section about the relationship between the structure, solubility and absorption of vitamins. In Chapter 13, there is a section about which is healthier butter or margarine (saturated fats vs. trans fats). In Chapter 14, there is a detailed section about metabolism of alcohol that explains the toxicity of alcohol for pregnant women (based on enzymatic oxidation of alcohol). In Chapter 15, there is a section about the odor of a molecule (determined by its shape rather than its functional groups). In Chapter 16, there is a detailed section about the chemistry of vision in the rod cells centers around the aldehyde 11-cis-retinal. In Chapter 17, there is a section about how the soap cleans dirt (the reasons for micelles formation) or the use of fake fats olestra in snacks (lipase cannot hydrolyze these fats). In Chapter 18, there is a detailed section about the effects of natural and synthetic amines on the human body including antihistamine, neurotransmitters, serotonin, nicotine and acetyl choline.

\section{BIOCHEMISTRY CHAPTERS}

Smith covers the biochemistry in the last 6 chapters that includes lipids, carbohydrates, amino acids, proteins, and enzyme, nucleic acids and protein synthesis, digestion and the conversion of food into energy and metabolism. The chapter on lipids includes details about membranes and sex hormones. The chapter on carbohydrate classifies sugars and health topics such as insulin function and human blood types based on the coating sugars. The chapter on proteins discusses all the amino acids, the structures of proteins including primary, secondary, tertiary and quaternary structures and then it discusses the function of enzymes and its interaction with drugs. The 
chapter on nucleic acid includes details about DNA, RNA, gene code, transcription and translation.

\section{STRENGTH OF THE TEXTBOOK}

The text includes many worked out problems as examples; a great help to do in-chapter exercises and end of the chapter problems; it also has very useful set of appendices that offers useful mathematical concepts and selected answers to in-chapter and end-of-chapter problems. This text is also part of the McGraw-Hill Connect Chemistry web-based assignment and assessment platform system that gives students the means to be in a better connect with their coursework and with their instructors. With Connect Chemistry, instructors can easily post assignments, quizzes, homework, and practice exams to test important skills of students at their own pace and on their own schedule (24/7 online access). The instructor also has the privilege to use McGraw-Hill Connect Chemistry linked to the blackboard to collect grades and post announcements. The instructor resources include solution to the textbook problems, test bank and plenty of videos and illustrations.

It has been our experience that many students in allied health major(s) are under the impression (definitely during the beginning days in a chemistry class) that the concepts presented in a freshmen chemistry classes have no relevance whatsoever in their profession or in real life. A chemistry textbook that "shows" real applications/ connection is more than welcome. Smith has successfully illustrated how chemistry explains many aspects of everyday life in every single chapter of her book. In each chapter, Smith uses the (P.A.V.E. or Practice, Apply, Visualize and Engage) way to student learning. For Practice, she uses the typical stepped-out practice problems and end-of-chapter problems categorized sequentially by topic to match chapter organization and also she uses the "How-To" boxes that offer step-by-step strategies for difficult concepts. And for apply, she includes a section(s) at the end of each chapter called "Focus on Health \& Medicine", and/or "Focus on the Human Body", and/or "Focus on the Environment" throughout the text. For visualize, she uses dynamic art work that brings together macroscopic and microscopic representations of images to help students comprehend on a specific anatomic region of the human body or a physiological function at the microscopic level. In addition to that, visual molecular modules have been used in the book. And finally for Engage, Smith grabs the student's attention to consumer, environmental, and health-related fields of the topics with today's to-the-point style of reading. In addition to that, very good visual modules have been used in the book.

\section{FINAL REMARKS}

No textbook in the market is perfect. Instructors may opt for a custom version of this one to meet the needs of the courses they teach. Instructors don't have to use this book verbatim. The theory of hybridization for example, is not presented in the book and if an instructor considers the topic crucial, it can be easily incorporated. Some of us have expanded the presentation on electron configurations and Periodic Table and reduced the topic on colligative properties. If a faculty is seeking a textbook to support teaching chemistry to health science majors, this text book can be one of the good choices.

\section{TEXTBOOK INFORMATION}

General, Organic, and Biological Chemistry, 2nd ed., by Janice Gorzynski Smith. McGraw-Hill Companies: Dubuque, Iowa, 2013. 944 pp. ISBN: 9780073402789 (hardcover). \$242.00.

\section{REFERENCES}

[1] Steitz, J. (2003) BIO2010—New challenges for biology educators. Cell Biology Education, 2, 87-91. http://dx.doi.org/10.1187/cbe.03-02-0005

[2] National Research Council (2013) BIO2010 transforming undergraduate education for future research biologists. National Academies Press, Washington DC. http://books.nap.edu/catalog/10497.html

[3] Pursell, P.D. (2012) Review of a life scientist's guide to physical chemistry. Journal of Chemical Education, 89, 1487-1488.

[4] El-Ashmawy, A. (2012) Review of chemistry for today, general, organic and biochemistry, 7th edition. Journal of Chemical Education, 89, 435-436. 